\title{
Effects of Titanium and Oxygen Content on Microstructure in Low Carbon Steels
}

\author{
Sang-Yoon Lee ${ }^{1, *}$, Young Joo $\mathrm{Oh}^{2}$ and Kyung-Woo $\mathrm{Yi}^{1}$ \\ ${ }^{1}$ School of Materials Science and Engineering, Seoul National University, Seoul 151-742, Korea \\ ${ }^{2}$ Metal Processing Research Center, Korea Institute of Science and Technology, Seoul 136-791, Korea
}

\begin{abstract}
The effects of the titanium and oxygen concentration on the characteristics of inclusions and microstructure in low carbon wrought steels were investigated. Increasing the titanium concentration from 48 to $120 \mathrm{ppm}$ promoted the formation of TiN particles and decreased the prior austenite grain size. The fraction of intragranular ferrite in the microstructure was relatively unchanged. When the oxygen concentration was increased from 50 to $130 \mathrm{ppm}$, the volume fraction and the number of inclusion increased. However, the fraction of intragranular ferrite in microstructures decreased abruptly above $80 \mathrm{ppm}$ because the allotriomorph ferrite phase at the prior austenite grain boundary began to form.
\end{abstract}

(Received October 19, 2001; Accepted January 15, 2002)

Keywords: non-metallic inclusion, intragranular ferrite, titanium, oxygen, microstructure

\section{Introduction}

For several decades, many researchers have strived to improve mechanical properties in wrought steels, such as strength, toughness and ductility. ${ }^{1-3)}$ Intragranular ferrite is known to provide an optimal combination of high strength and good toughness due to refined grain size and interwoven structure. ${ }^{4)}$ It has been reported that intragranular ferrite nucleates mainly at the surface of non-metallic inclusion ${ }^{5)}$ and secondary nucleation occurred through sympathetic nucleation from the ferrite laths. ${ }^{6)}$ However, it has been recognized that intragranular ferrite rarely observed in wrought steels because oxide particles have a lower density than weld metals.

Titanium-nitride, ${ }^{7)}$ aluminum-rich inclusions, ${ }^{8)}$ manganese-sulfide $^{9)}$ and titanium-oxide ${ }^{10,11)}$ have been reported to be effective in stimulating nucleation of intragranular ferrite because they work as the heterogeneous nucleation sites of ferrite. Among them, $\mathrm{Ti}_{2} \mathrm{O}_{3}$ was known as the most effective one.

Several factors influencing the formation of intragranular ferrite have been reported. ${ }^{12)}$ They are the density of the inclusions, the size distribution of the inclusions, the type of inclusions and the prior austenite grain size. These factors are determined by the steel composition and the solidification rate. Many studies on the characteristics of inclusions as a ferrite nucleation site have been reported. Goto et al. ${ }^{13,14)}$ investigated the effect of the solidification rates on the composition and size distribution of the inclusions. Guo et al. ${ }^{15)}$ reported the effect of the size distribution of the inclusions on the microstructure. Hong et al. ${ }^{16)}$ modeled the growth and dissolution of inclusions in weld metals. In the present work, the effects of the composition, especially titanium and oxygen, on the characteristics of non-metallic inclusions and microstructures in low carbon steels were investigated.

${ }^{*} \mathrm{Ph}$. D candidate, Seoul National University.

\section{Experimental Procedure}

Low carbon specimens with different compositions were prepared using a vacuum induction melting and casting furnace. The chemical compositions of the specimens are given in Table 1.

The ingots were homogenized at $1373 \mathrm{~K}$ for $36 \mathrm{ks}$. Then, samples for investigation were cut from a quarter height of each ingot. The number of inclusions within an area of $360 \times$ $360 \mu \mathrm{m}^{2}$ were counted using scanning electron microscopy $(\mathrm{SEM})$ in backscattered mode. Several researchers ${ }^{17,18)}$ have reported that inclusions between 0.2 and $6.0 \mu \mathrm{m}$ in diameter could nucleate the intragranular ferrite. Therefore, the same range of non-metallic inclusions were counted in this study. The chemical analysis was carried out for more than 100 inclusions in each specimen by transmission electron microscopy (TEM) with energy dispersive spectroscopy (EDS).

The volume fraction of inclusions, $V$, was calculated by eq. (1). The harmonic mean of the inclusion diameters, $d$, and the number of inclusions per unit volume, $N_{v}$, were obtained using eqs. (2) and (3) which were proposed by DeHoff. ${ }^{19)}$

$$
\begin{aligned}
V & =\frac{\pi}{6} d^{3} N_{v} \\
N_{v} & =\frac{2}{\pi} \frac{N_{A}}{d} \\
\frac{1}{d} & =\frac{1}{n} \sum_{i} \frac{1}{d_{i}}
\end{aligned}
$$

where $d_{i}$ is the apparent diameter of the $i^{\text {th }}$ inclusion among $n$ inclusions, $N_{A}$ is the number of inclusions per unit area.

In order to investigate the microstructures, the samples were forged then machined to cylindrical specimens $8 \mathrm{~mm}$ in diameter and $12 \mathrm{~mm}$ in length. These specimens were austenized at $1523 \mathrm{~K}$ for $600 \mathrm{~s}$ and then continuously cooled at $5 \mathrm{~K} / \mathrm{s}$ to room temperature. The thermomechanical treatment was performed using a thermomechanical simulator (ThermecMastor-Z).

All specimens were polished and etched in $2 \%$ Nital for optical microscopy. The prior austenite grain size and the 
Table 1 Chemical composition of specimens (mass\%).

\begin{tabular}{|c|c|c|c|c|c|c|c|c|}
\hline & $\mathrm{Ti}$ & $\mathrm{O}$ & $\mathrm{N}$ & $\mathrm{C}$ & $\mathrm{Mn}$ & $\mathrm{Si}$ & $S$ & $\mathrm{P}$ \\
\hline Specimen 1 & 0.0090 & 0.005 & 0.002 & 0.04 & 1.74 & 0.23 & 0.003 & 0.0028 \\
\hline Specimen 2 & 0.0048 & 0.005 & 0.002 & 0.051 & 1.76 & 0.20 & 0.005 & 0.0027 \\
\hline Specimen 3 & 0.0120 & 0.005 & 0.001 & 0.055 & 1.75 & 0.19 & 0.006 & 0.0073 \\
\hline Specimen 4 & 0.0081 & 0.007 & 0.001 & 0.049 & 1.79 & 0.20 & 0.005 & 0.0028 \\
\hline Specimen 5 & 0.0100 & 0.010 & 0.002 & 0.050 & 1.72 & 0.21 & 0.005 & 0.0035 \\
\hline Specimen 6 & 0.0120 & 0.013 & 0.002 & 0.052 & 1.56 & 0.10 & 0.004 & 0.0031 \\
\hline
\end{tabular}

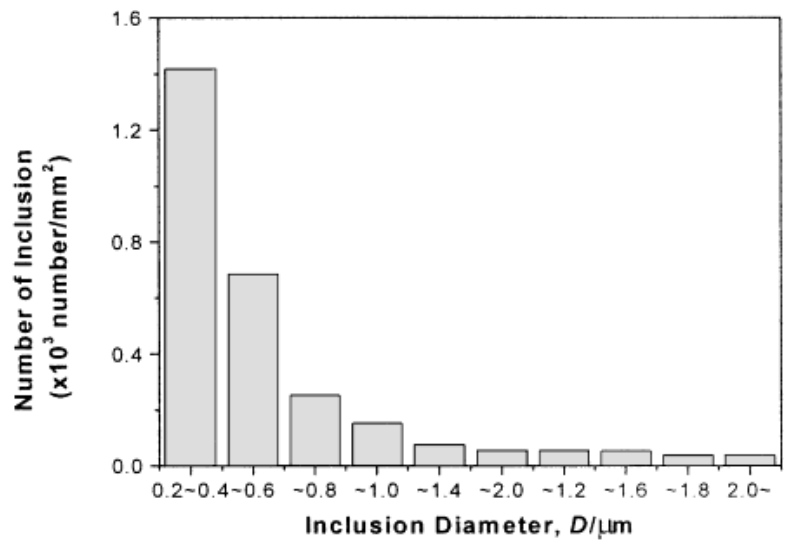

Fig. 1 Size distribution of inclusions in specimen. (a)

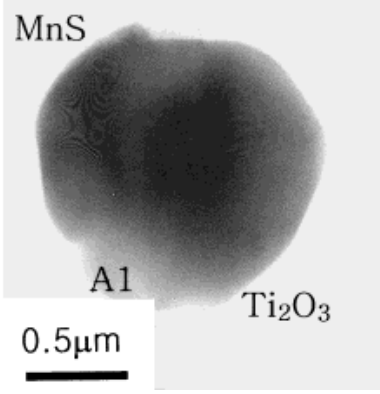

(b)

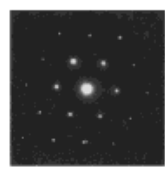

$B=[0001]$

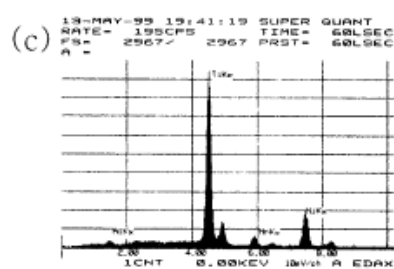

Fig. 2 A typical TEM replica micrograph of $\mathrm{Ti}_{2} \mathrm{O}_{3}$ and $\mathrm{MnS}$. (a) TEM micrograph (b) electron diffraction $\operatorname{spot} \operatorname{pattern}(\mathrm{B}=[0001])$ at $\mathrm{A} 1 . \quad(\mathrm{c})$ EDS spectrum.

fraction of intragranular ferrite (IGF) were measured with an image analyzing computer program (Image-Pro. v3.0).

\section{Results and Discussion}

\subsection{Effects of titanium and oxygen contents on charac- teristics of inclusions}

The typical size distribution of the inclusions is shown in Fig. 1. The inclusions in this study were within the range $0.2-2.5 \mu \mathrm{m}$ and most inclusions were smaller than $1 \mu \mathrm{m}$.

The TEM replica micrographs of a typical inclusion in specimen 1 are shown in Figs. 2 and 3. The majority of the inclusions were spherical oxides and angular nitride. EDS and diffraction analysis indicated that the phases of the spherical and angular inclusions were $\mathrm{Ti}_{2} \mathrm{O}_{3}$ and $\mathrm{TiN}$, respectively. Most TiN particles were less than $0.5 \mu \mathrm{m}$ in diameter. In addition, precipitated $\mathrm{MnS}$ was observed on the surface of $\mathrm{Ti}_{2} \mathrm{O}_{3}$ and TiN particles. (a)

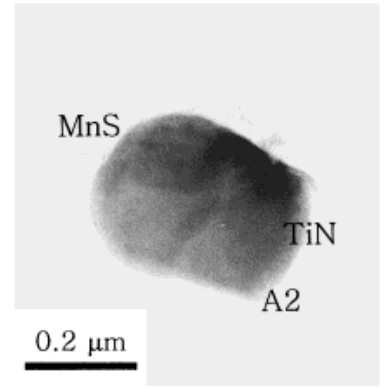

(b)

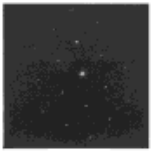

$\mathrm{B}=[110]$

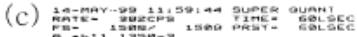

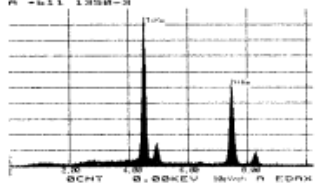

Fig. 3 A typical TEM replica micrograph of TiN and MnS. (a) TEM micrograph (b) electron diffraction $\operatorname{spot} \operatorname{pattern}(B=[110])$ at A2. (c) EDS spectrum.

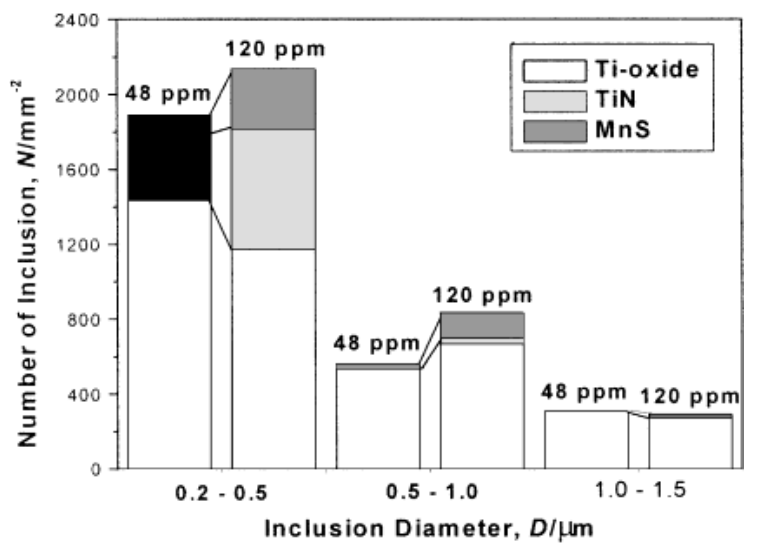

Fig. 4 Effect of titanium concentration on composition of inclusions (specimen 2,3).

Figure 4 shows the change of composition ratio of the inclusions with the change in the titanium concentration. Although light elements, such as oxygen and nitrogen, were not counted with EDS, the type of inclusions could be recognized as Ti-oxide and MnS, Ti-Mn-oxide and $\mathrm{MnS}$, TiN and $\mathrm{MnS}$, by the apparent difference in shape and the diffraction patterns of the inclusions. When the titanium concentration was increased from 48 to $120 \mathrm{ppm}$, it was realized that there was a relative increase in the number of tiny TiN particles compared to specimen 3. However, the total volume fraction of the inclusions did not change as shown in Fig. 5. Therefore, increasing the titanium concentration appears to promote the formation of tiny TiN particles that are unable to increase the total volume fraction of inclusions.

In contrast, the effects of the oxygen concentration on the size distribution and type of inclusions differ according to the titanium concentration. As oxygen concentration is increased from 50 to $100 \mathrm{ppm}$, the change in the inclusions type have 


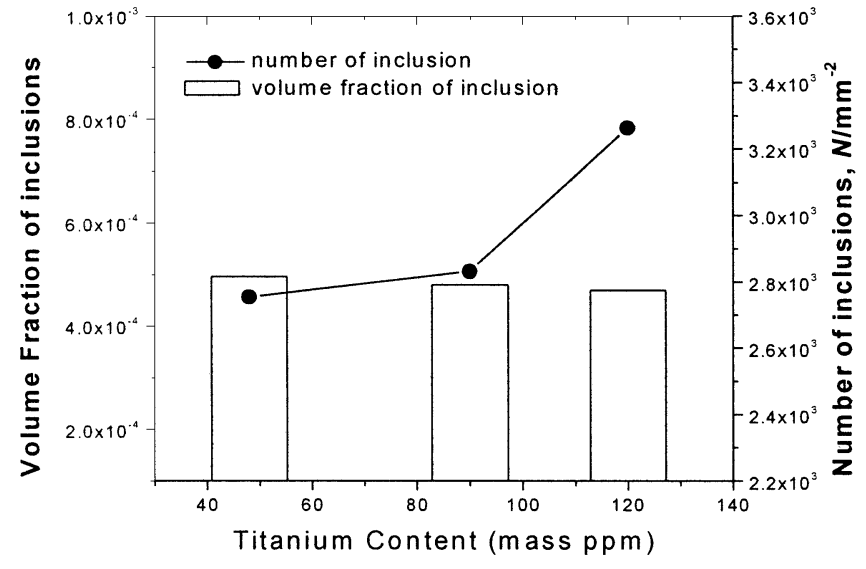

Fig. 5 Effects of titanium concentration on number and volume fraction of inclusion.

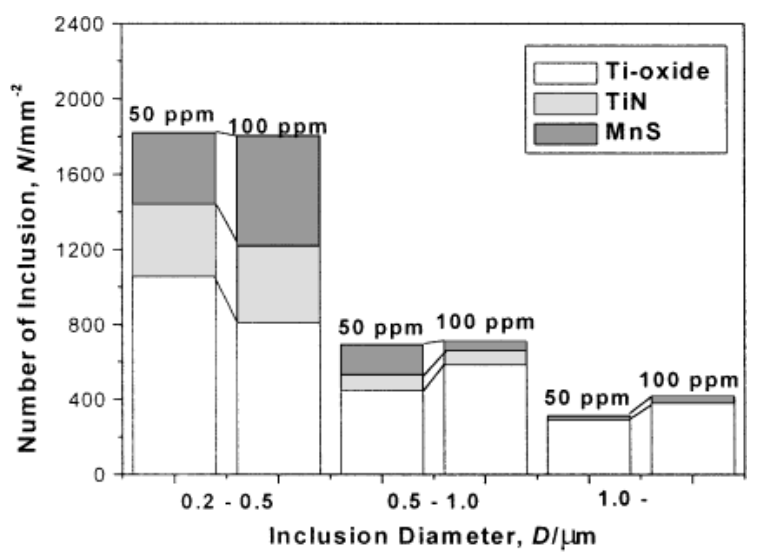

Fig. 6 Effect of oxygen concentration on composition of inclusions (specimen 1,5).

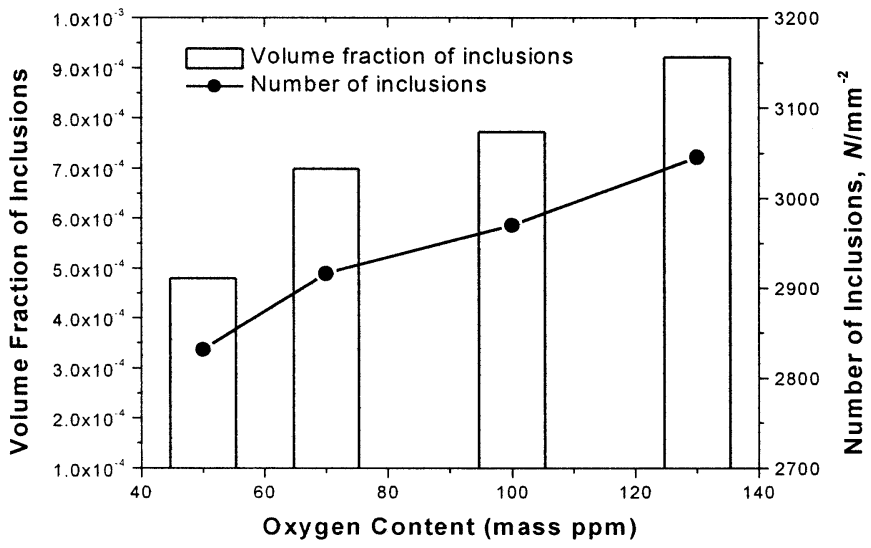

Fig. 7 Effects of oxygen concentration on number and volume fraction of inclusions.

not been observed (Fig. 6). However, the volume fraction and the total number of inclusions increased (Fig. 7). Therefore, it is believed that the increase in the oxygen concentration led to form of large enough inclusions to contribute the variation of the volume fraction of inclusions.

\subsection{Effects of titanium and oxygen content on mi- crostructures}

Figure 8 shows the microstructures with as a function of the titanium concentration. Although the titanium concentration was increased from 48 to $120 \mathrm{ppm}$, both the microstructures (a)

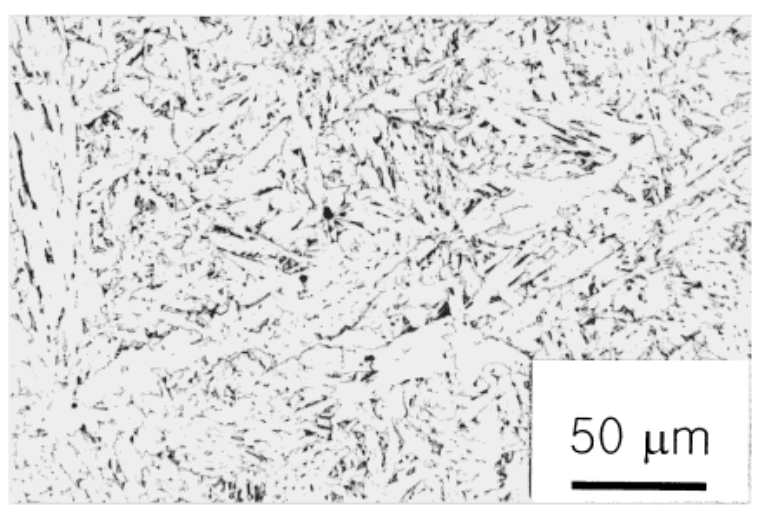

(b)

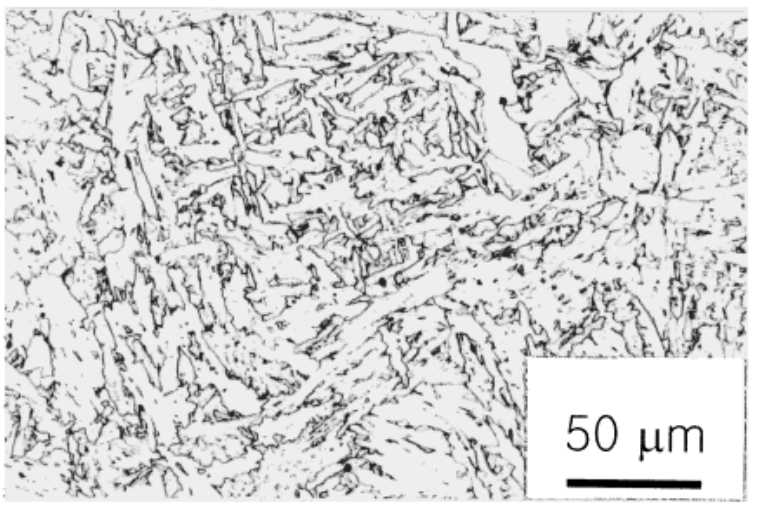

Fig. 8 Effect of titanium concentration on the microstructure. (a) specimen 2, (b) specimen 3 .

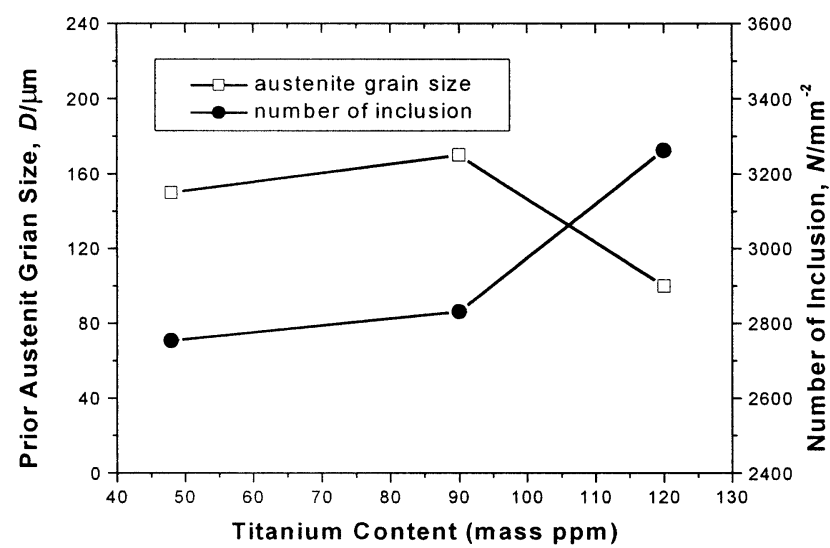

Fig. 9 Variation of prior austenite grain size and number of inclusion with increasing titanium concentration.

were a mix of bainite and intragranular ferrite and were quite similar.

Figure 9 shows the variation of the prior austenite grain size and the number of inclusions with increasing titanium concentration. As mentioned above, when the titanium concentration increases from 90 to $120 \mathrm{ppm}$, the number of inclusions increases. On the other hand, the prior austenite grain size decreased from 150 to $100 \mu \mathrm{m}$. It appears that the tiny TiN particles restricted the growth of the prior austenite grain by pinning the austenite grain boundary.

Early reports $^{20}$ ) showed that the minimum diameter of TiN particles needed to nucleate intragranular ferrite in low carbon steels was approximately $200 \mathrm{~nm}$ and the increase in the number of inclusions promotes the formation of intragranu- 


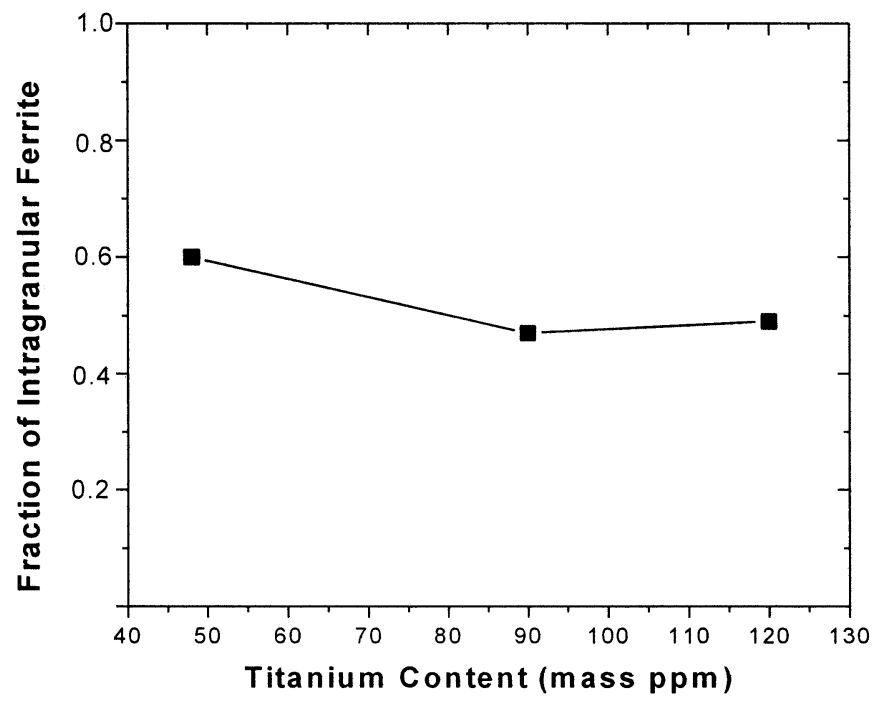

Fig. 10 Variation of fraction of intragranular ferrite with increasing titanium concentration.

lar ferrite due to increasing intragranular inclusion surface area. Also, Oh et al. ${ }^{21)}$ reported that the critical prior austenite grain size for stable formation of intragranular ferrite should be larger than $100 \mu \mathrm{m}$ and the fraction of intragranular ferrite increased with increasing prior austenite grain size up to $350 \mu \mathrm{m}$. In particular, at austenite grain sizes between $100 \mu \mathrm{m}$ and $350 \mu \mathrm{m}$, the larger austenite grain size, the more intragranular ferrite was formed. Because the prior austenite grain size decreased, even though the number of inclusions increased (Fig. 9), the fraction of intragranular ferrite appeared similar value (Fig. 10).

Figure 11 shows effect of the oxygen concentration on the microstructures. The microstructures consisted of a mix of intragranular ferrite and bainite below $100 \mathrm{ppm}$ oxygen but allotriomorph ferrite nucleated and grown at prior austenite grain boundary was also observed as well as intragranular ferrite at above $100 \mathrm{ppm}$ oxygen.

The variation in the fraction of intragranular ferrite with increasing oxygen concentration is shown in Fig. 12. The prior austenite grain size was almost constant at $150 \mu \mathrm{m}$. Although the number and the volume fraction of inclusions increased (Fig. 6), the fraction of intragranular ferrite decreased abruptly at an oxygen concentration of approximately 80 ppm. Previous reports ${ }^{11,21)}$ shows that the increase in the volume fraction of inclusions promoted the increase in the intragranular ferrite phase because of the increased number of ferrite nucleation sites. The decrease in the fraction of intragranular ferrite appears to be attributed to the formation of allotriomorph ferrite, which nucleated at the prior austenite grain boundary.

To exclude the influence of allotriomorph ferrite on the intragranular ferrite fraction, one sample (specimen 6) was austenized at $1623 \mathrm{~K}$ (Fig. 13). The prior austenite grain size was above $300 \mu \mathrm{m}$ and the fraction of intragranular ferrite increased up to 0.7. It is assumed that the fraction of intragranular ferrite decreased at oxygen concentrations greater than above $100 \mathrm{ppm}$ because allotriomorph ferrite formation at prior austenite grain boundary prevented the nucleation of intragranular ferrite at the surface of the inclusions.

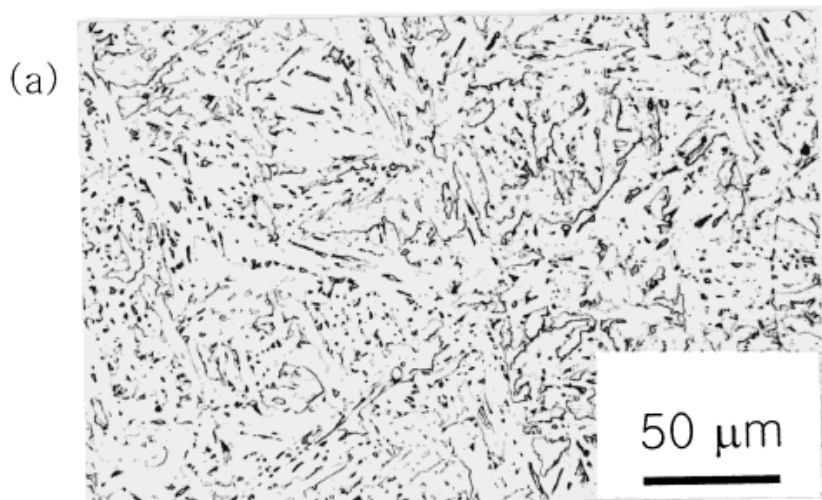

(b)

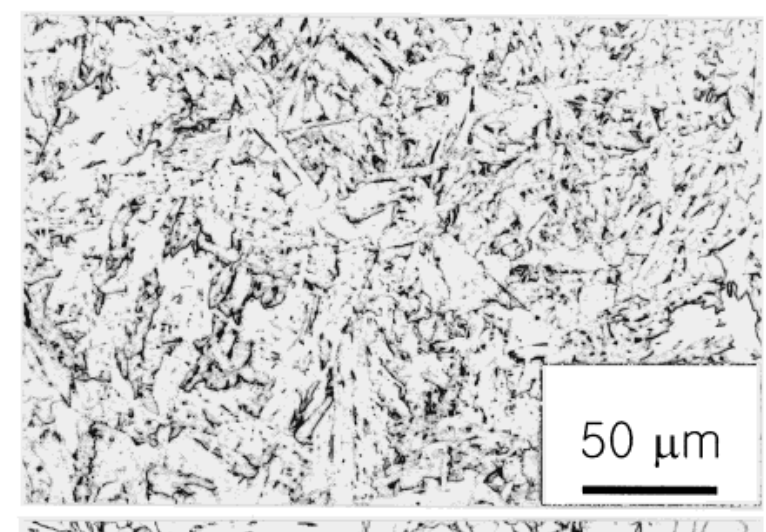

(c)

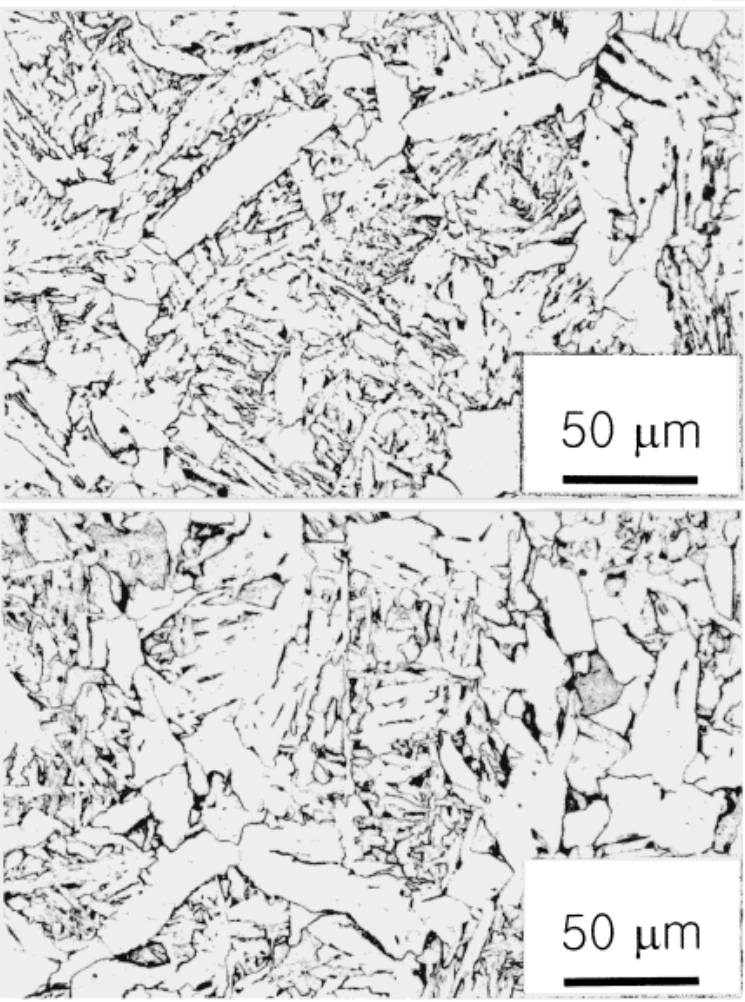

Fig. 11 Effect of oxygen concentration on the microstructure. (a) specimen 1, (b) specimen 4, (c) specimen 5, (d) specimen 6.

Many studies ${ }^{9,22)}$ reported that increasing oxygen concentration promoted ferrite formation at the prior austenite grain boundary. In particular, when the prior austenite grain size was not large enough like in the present study, ferrite formation at the prior austenite grain boundary may seriously affect the fraction of intragranular ferrite. 


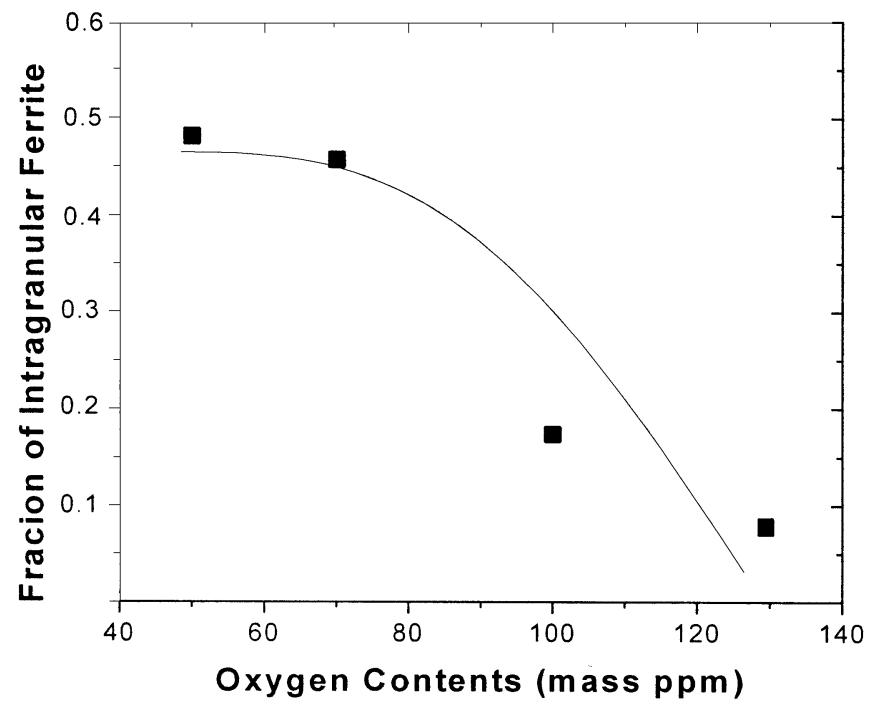

Fig. 12 Variation of fraction of intragranular ferrite with increasing oxygen concentration.

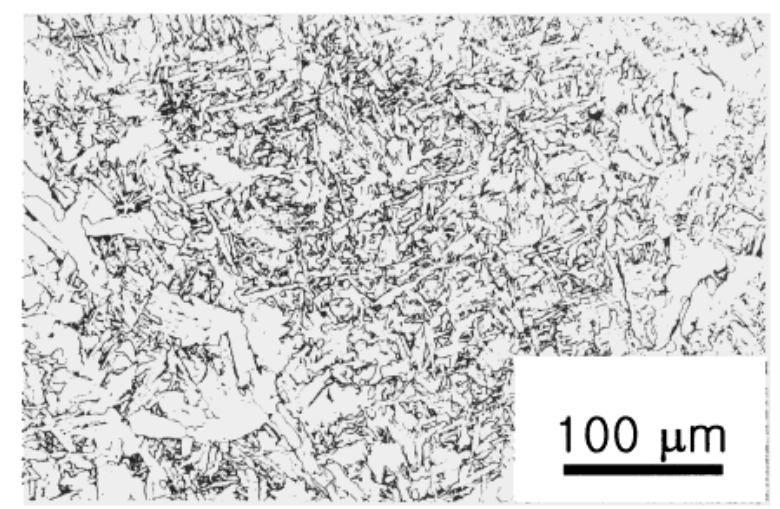

Fig. 13 Optical micrograph of specimen 6 after austenization at $1623 \mathrm{~K}$ for $10 \mathrm{~min}$.

\section{Conclusions}

The effect of the titanium and oxygen concentration in low carbon steels on the characteristics of the inclusions and microstructures were investigated. With increasing titanium concentration, the number of inclusions increased but the volume fraction and microstructures were unchanged. With increasing oxygen concentration, the number and volume fraction of inclusions increased. However, the fraction of intragranular ferrite decreased at oxygen concentration above $80 \mathrm{ppm}$ because allotriomorph ferrite formed at the prior austenite grain boundary.

\section{REFERENCES}

1) H. Takechi: Tetsu-to-Hagane 68 (1982) 1244-1255.

2) S. Hashimoto, M. Sudo, K. Himura and T. Hosoda: Trans. ISIJ 40 (1986) 985-992.

3) W.-Y. Choo: J. Kor. Inst. Met. Mater. 36 (1998) 1945-1958.

4) H. K. D. H. Bhadeshia: Bainite in Steel, (Cambridge Univ. Press, UK, 1992).

5) R. A. Farrar and P. L. Harrison: J. Mater. Sci. 22 (1987) 3812-3820.

6) F. J. Babaro, P. Krauklis and K. E. Eastering: Mater. Sci. Tech. 5 (1989) 1057-1068.

7) S. Kanazawa, A. Nakashima, K. Okamoto and K. Kanaya: Trans. ISIJ 16 (1976) 486-495.

8) A. R. Bhatti, M. E. Saggese, D. N. Hawkins, J. A. Whiteman and M. S. Golding: Weld. J. 63 (1984) 224s-230s.

9) D. J. Abson, R. E. Dolby and P. H. M. Hart: in Trends in Steels and Consumable for Welding, (the Welding Institute, London, 1978) pp. 75101.

10) H. Homma, S. Ohkita, S. Matsuda and K. Yamamoto; Weld. J. 66 (1987) 301s-309s.

11) J.-L. Lee and Y.-T. Pan: Metall. Trans. A 22A (1991) 2818-2822.

12) J.-L. Lee and Y.-T. Pan: Metall. Trans. A 24A (1993) 1399-1408.

13) H. Goto, K. Miyazawa, K. Yamaguchi, S. Ogibayashi and K. Tanaka: Trans. ISIJ 34 (1994) 414-419.

14) H. Goto, K. Miyazawa, W. Yamada and K. Tanaka: Trans. ISIJ 35 (1995) 708-714.

15) M. Guo and H. Suito: Trans. ISIJ 39 (1999) 678-686.

16) T. Hong, T. Debroy, S. S. Babu and S. A. David: Metall. Mater. Trans. B $31 B$ (2000) 161-169.

17) I. deS. Bott and P. R. Rios: Scr. Meter. 38 (1998) 1269-1274.

18) Z. Zhang and R. A. Farrar: Mater. Sci. Tech. 12 (1996) 237-260.

19) R. T. DeHoff: Quantitative Microscopy, (McGraw-Hill Book Company, New York, 1968) p. 128.

20) Y. Morikage, K. Oi, F. Kawabata and K. Amano: Tetsu-to-Hagane 84 (1998) 40-45.

21) Y.-J. Oh, S.-Y.Lee, J.-S. Byun, J.-H. Shim and Y. W. Cho: Mater. Trans., JIM 41 (2000) 1663-1669.

22) P. F. Chaveriat, G. S. Kim, S. Shah and J. E. Indcochea: J. Mater. Eng. 9 (1987) 253-267. 